\title{
A pilot study of cadre training to promote responsible self- medication in Indonesia: Which is better specific or general modules?
}

\author{
Yosi Wibowo Ph.D ${ }^{1}$ (D) | Adji P. Setiadi Dr. ${ }^{1}$ (D) | Steven V. Halim M.Pharm. ${ }^{1}$ | \\ Rama D. Saputra B.Pharm. ${ }^{2}$ | Rizka Oktavia B. Pharm. ${ }^{2}$ | Rizky Irianti B. Pharm. ${ }^{2}$ | \\ Putri I. Lestari B. Pharm ${ }^{2}$ | Cecilia R. Puspitasari B.Pharm. ${ }^{2}$ | Bruce Sunderland Ph.D. $^{3}$
}

\footnotetext{
${ }^{1}$ Centre for Medicines Information and Pharmaceutical Care (CMIPC), Faculty of Pharmacy, Universitas Surabaya, Surabaya, Indonesia

${ }^{2}$ Faculty of Pharmacy, Universitas Surabaya, Surabaya, Indonesia

${ }^{3}$ School of Pharmacy, Faculty of Health Sciences, Curtin University, Perth, Western Australia, Australia
}

Correspondence

Dr. Yosi Irawati Wibowo, Centre for Medicines Information and Pharmaceutical Care (CMIPC), Faculty of Pharmacy, Universitas Surabaya, 5th Floor, Building FF, J. Raya Kalirungkut, Surabaya 60293, Jawa Timur, Indonesia.

Email:yosi_wibowo@staff.ubaya.ac.id

Funding information

This work was not supported by any funding.

\begin{abstract}
In 2015, the Indonesian Government initiated 'Smart Use of Medications Movement' ('GeMa CerMat') which included cadre training to promote responsible self-medication. Evaluation of a pilot training conducted across Indonesia suggested the need to improve those training modules. This study aimed to assess cadre' knowledge gained following training with newly developed general or specific training modules. Five types of modules were developed and used to train cadres at five Community Health Centres (CHCs) in Surabaya, Indonesia: 1) Sidosermo CHC (general-drugs module), 2) Tenggilis $\mathrm{CHC}$ (common cold drugs module), 3) Gunung Anyar CHC (analgesic drugs module), 4) Kalirungkut $\mathrm{CHC}$ (anti-diarrhoeal drugs module), and 5) Jagir $\mathrm{CHC}$ (indigestion drugs module). Cadres' knowledge improvements were evaluated using pre-/ post-test scores and the difference scores depending on the module being tested. Multifactorial ANOVA explored the effects of the type of module on difference scores. A total of 279 cadres across five $\mathrm{CHCs}$ were involved in the training, giving response rates from $65 \%$ to $93 \%$. There was an increase in the post-test scores after the training with all modules. However, significant differences were reported only for the specific-drugs module groups (all $p<.001$ ). Furthermore, the general module group had the lowest difference score $(1.12 ; 95 \% \mathrm{Cl}[-0.45,2.92])$ while the common cold module group had the highest gain $(5.02 ; 95 \% \mathrm{Cl}[1.95,5.17])$. Multifactorial ANOVA revealed that there was a significant main effect of the type of modules on difference scores $[F(4,263)=8.37, p<.001]$. In conclusion, this preliminary study indicated that the development of modules for specific minor illnesses could be beneficial in facilitating effective community-based training to promote responsible selfmedication in Indonesia. The priority for therapeutic areas chosen for the module should be based on the local needs. Further research is required to confirm the findings in broader community members.
\end{abstract}

KEYWORDS

cadre training, Indonesia, module, self medication 


\section{1 | INTRODUCTION}

Indonesia is the world's largest archipelagic country with a current population of around 260 million (Statistics Indonesia, 2018). This large population presents challenges for access to healthcare in light of the limited health resources, as well as the increasing burden of non-communicable diseases in Indonesia (Republic of Indonesia (Rol) 2012; World Health Organisation, 2011). Hence, it is a priority of the Indonesian Government to improve the quality of life among Indonesians through a 'Healthy Indonesia' program. The program included three key components: 1) promoting a healthy living paradigm, 2) strengthening health services/facilities, and 3) implementing national health coverage (Jaminan Kesehatan Nasional - JKN) to provide basic healthcare to all Indonesians. Strategies to promote a healthy living paradigm include health promotion, disease prevention/control, as well as community empowerment (MoH-RI, 2016).

In 2015, the Indonesian Government initiated a national health program, 'Smart Use of Medications Movement' (Gerakan Masyarakat Cerdas Menggunakan Obat - 'GeMa CerMat') aiming to empower the Indonesian community to practice responsible self-medication (Directorate General of Pharmaceutical and Medical Devices MoH-RI, 2015). The World Health Organisation (WHO) defines self-medication as "the selection and use of medicines by individuals to treat self-recognised illnesses or symptoms" (WHO, 1998); it generally includes recognising or self-diagnosing symptoms or sickness, selecting medicines, administering medicines, and monitoring the outcomes (Holt \& Hall, 1990). A population survey in Indonesia reported that $90.5 \%$ of Indonesians had practiced self-medication, indicating that self-medication has a pivotal role as the first action taken by Indonesians in their healthcare (Statistics Indonesia, 2014). Hence, promoting responsible self-medication through 'GeMa CerMat' is expected to move the Indonesian community towards greater independence to treat their minor ailments, thus optimising the use of health resources for minor ailments.

The initial step of 'GeMa CerMat' was to improve community knowledge on medication through community training with health professionals as trainers. Pharmacists - with their expertise in medications - are expected to be actively involved as trainers in the training (MoH-RI, 2015). Studies worldwide have reported the role of pharmacists in facilitating community members when purchasing non-prescription medications through pharmacies (Brata, Gudka, Schneider, \& Clifford, 2014; Piecuch \& KozlowskaWojciechowska, 2013; Rutter, 2015; Schneider et al., 2011 Suleiman, 2013). However, little is reported regarding pharmacists' proactive role in community education and empowerment to encourage responsible self-medication. Prior studies in Indonesia reported that the involvement of pharmacists in community-based interactive training improved knowledge and attitude of patients with diabetes and tuberculosis (Hartayu, Izham, \& Suryawati, 2012; Susantini, 2006); the approach was then adopted to conceptualise community training in promoting responsible self-medication as part of the 'GeMa CerMat' program (MoH-RI, 2015).

\section{What is known about the topic}

- Studies worldwide have reported self-medication practices as well as pharmacists' role in facilitating/ counselling community members when purchasing nonprescription medications through pharmacies.

- Prior studies in Indonesia reported the potential role of pharmacists in training to improve knowledge and attitude towards adherence among patients with chronic diseases.

\section{What this paper adds}

- Training by pharmacists has the potential to improve Over-the-Counter (OTC) medicines literacy among Indonesian cadres in order to promote communitybased responsible self-medication.

- Modules focusing on drugs for specific minor illnesses facilitate better learning outcomes than general modules; the priority for therapeutic areas chosen for the modules should be based on the local needs and characteristics of the local communities.

In 2016, a 'GeMa CerMat' pilot training program was carried out across Indonesia. The training focused on cadres, i.e., local community members who were trained to assist with health activities organised by Community Health Centres ( $\mathrm{CHCs}$ ), to prepare them as 'change agent'. A module was developed to guide the training; the module consisted of three activities: 1 ) medication classification, 2) information on the medication label/package (i.e., drug name and active ingredient, indication, directions for use, adverse effects and storage), and 3) other information (i.e., special dosage forms and disposal) (Setiadi et al., 2017). The pilot training was then evaluated using focus group discussions with the pharmacist/pharmacy staff trainers. Some of the key findings from the discussions were the need to revise the current education modules in terms of its content and structure as well as the need to focus on the specific community needs (Setiadi et al., 2019). This present pilot study aimed to assess cadres' knowledge gained after training with newly developed general as well as disease specific training modules.

\section{2 | METHODS}

The data collection instrument and methodology used in this study were approved by the Ethics Committee of the Faculty of Medicine, Islamic University of Indonesia (No. 08/Ka.Kom.Et/70/KE/IX/2016).

This pilot study was conducted in Surabaya, the capital city of East Java Province and the second largest city in Indonesia. Surabaya covers 31 districts (kecamatan) with a population of approximately 3 million (Surabaya City Health Office, 2016). In 2015, there were 63 Community Health Centres (CHC, Puskesmas) in Surabaya, 
with a ratio of 0.22 per 1,000 population (Surabaya City Health Office, 2016). A CHC is a functional unit of the regional Health Office; and they are overseen under the Ministry of Health and provide access to primary health services in the district area $(\mathrm{MoH}-\mathrm{RI}$, 2014). Five CHCs located near the researchers' office in Universitas Surabaya (southern part of Surabaya) were selected as the pilot research settings: Jagir $\mathrm{CHC}$, Gunung Anyar $\mathrm{CHC}$, Kalirungkut $\mathrm{CHC}$, Tenggilis $\mathrm{CHC}$ and Sidosermo $\mathrm{CHC}$. This convenience sampling was used for this pilot study to provide preliminary data on the effectiveness of the new specific modules before conducting a larger study; also, the five $\mathrm{CHCs}$ had planned to conduct GeMa CerMat events within the study timeframe.

\subsection{Development of general and specific training modules}

Five training modules, including one general-drugs module and four specific-drugs modules ("indigestion drugs", "cough and cold drugs", "diarrhoea drugs" and"analgesics"), were drafted by the research team based on the evaluation feedback on the module used in the previous research (Setiadi et al., 2017, 2019); the four therapeutic areas chosen were among the most common minor illnesses treated in primary health facilities in East Java, Indonesia (Surabaya City Health Office, 2018). This was followed with an expert panel (consisting of four external experts - two pharmacists in the area of pharmacy practice or community pharmacy, and two policy makers) to discuss and finalise the module contents. The final modules included five basic competencies: 1) drug name and active ingredients, 2) drug indication, 3) drug classification, 4) drug directions for use, and 5) other information on medication label/package (adverse effects, expiry date, storage/disposal); differences between modules were based on the examples of drug included in the modules as well as the medication packs that accompanied the modules (Table 1 and Figure 1).

\subsection{Cadres training using general and specific modules}

The five modules developed were evaluated in cadres training programs across the five CHCs in Surabaya in October-November 2017;

\begin{tabular}{|l|l|}
\hline Drug Logo & Descriptions \\
\hline
\end{tabular}

FIGURE 1 Drug logo descriptions each module was randomly allocated to one CHC: 1) Sidosermo $\mathrm{CHC}$ (general-drugs module), 2) Tenggilis $\mathrm{CHC}$ (module for common cold drugs), 3) Gunung Anyar CHC (module for analgesic drugs), 4) Kalirungkut $\mathrm{CHC}$ (module for anti-diarrhoeal drugs) and 5) Jagir $\mathrm{CHC}$ (module for indigestion drugs).

The training initially focused on $\mathrm{CHC}$ cadres, i.e., local community members who were trained to assist with health activities organised by the local $\mathrm{CHC}$, as the training was expected to prepare them as 'change agents' for a broader uptake of the 'GeMa CerMat' initiative. At each research setting, lists of $\mathrm{CHC}$ cadres were obtained from the pharmacist-in-charge of the related $\mathrm{CHC}$. All of the $\mathrm{CHC}$ cadres listed were then invited verbally to participate in the training: Jagir CHC ( $n=85)$, Gunung Anyar $\mathrm{CHC}(n=85), \mathrm{CHC}$ Kalirungkut $(n=52)$, Tenggilis $\mathrm{CHC}(n=70)$, Sidosermo $\mathrm{CHC}(n=70)$. Each setting had different schedules of training. At the beginning of each training session, the researchers introduced the research and asked for participation; written consent was obtained from those willing to participate. Participants were then divided into small groups of approximately 10 people; each group was facilitated by a trainer using the developed modules. In this regard, 10 trainers were recruited from fourth-year pharmacy students in Universitas Surabaya (had completed/attended courses related to 'responding to symptoms' and 'clinical pharmacy'). They were briefed about the training modules and involved in a simulation training in April 2017 (under supervision of the researchers). The same trainers were involved in all settings.

Participants' knowledge of either the general-drugs or specific-drugs modules related to the five basic competencies included in the modules (Table 1) was evaluated using pre-/post-tests conducted just before and just after the training. The tests were developed by an expert panel (AP, YW, SV) and only differed in relation to the drugs used in the questions - which were chosen based on the modules (either general-drugs module; or specific-drug modules for indigestion, cough and cold, diarrhoea, or analgesics). For example, Question 5: "This [drug name] can be used is to treat [indication]". Each test included 15 questions; each question was scored ' 1 ' (for wrong answer) ' 2 ' (for can't tell) and ' 3 ' (for correct answer), thus providing a total score ranging from 15 to 45 . Similar tests have been used and validated in other studies (Setiadi et al., 2019). A short questionnaire obtained participant characteristics data were also included with the tests.

\section{3 | Data analysis}

IBM SPSS Statistics version 20.0 (IBM Corp, Armonk, NY, USA) was used for data analysis. Descriptive statistics summarised the participant characteristics across the five $\mathrm{CHCs}$ (five modules: general, indigestion, diarrhoea, analgesics, common cold and cough); characteristic differences were then evaluated using Kruskal-Wallis test or chi-square test, as appropriate. Participants' knowledge improvement across the five groups of modules was determined using pretest and post-test scores (differences between pre-test and post-test 


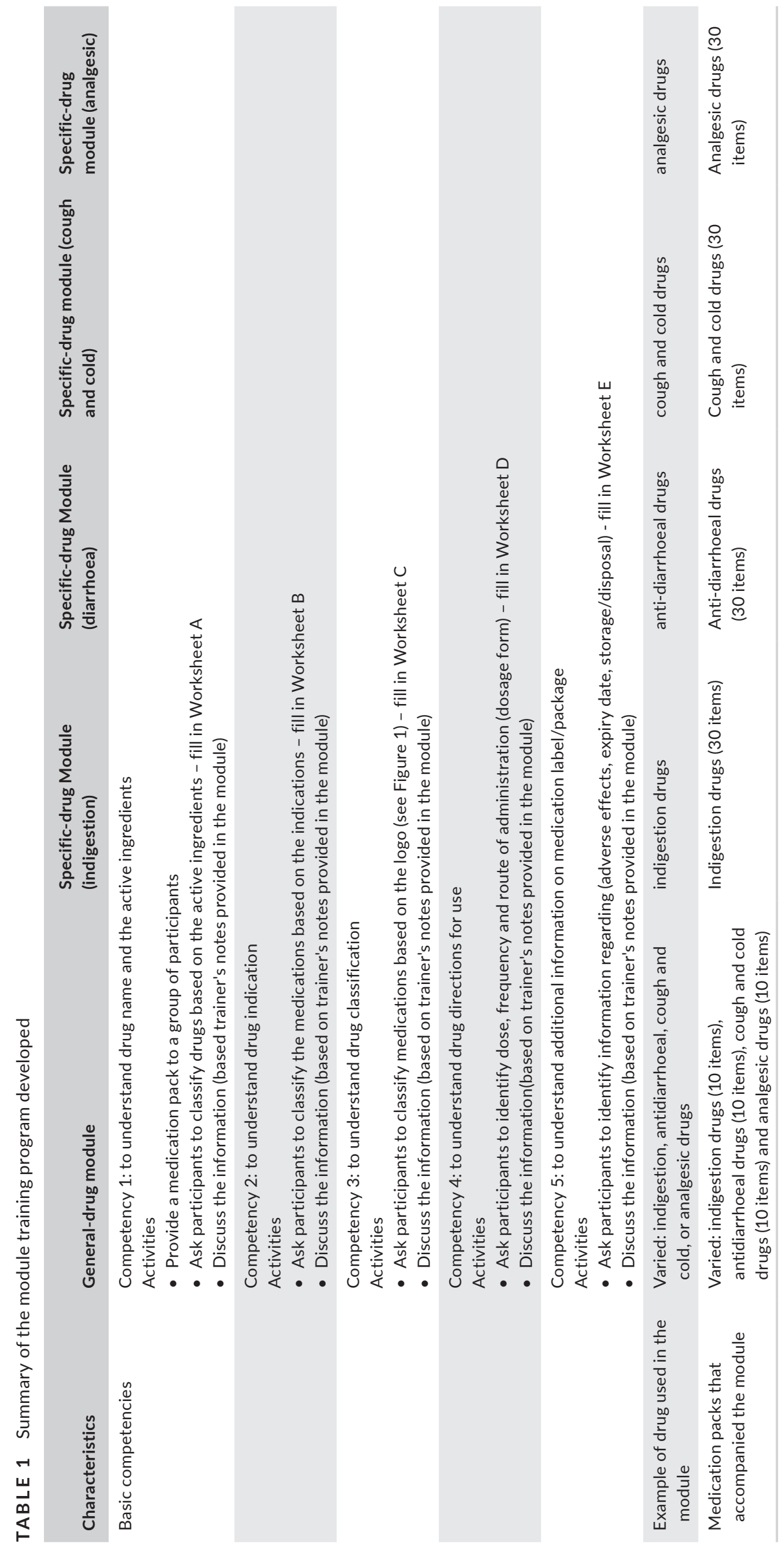


scores were analysed using Wilcoxon signed-rank test); the scores were calculated for each competency as well in total. In addition, the knowledge gain (score difference) was calculated by substracting the total pre-test scores from the total post-test scores for individual participants; the mean score differences $( \pm 95 \%$ confidence intervals) were also determined based on the combined data from each group. To explore whether type of module was associated with mean score knowledge gain, multifactorial analysis of variance (ANOVA) was used to account for other variables, i.e., participant demographics (age, gender, education, occupation, income) and self-medication frequencies. Bonferroni post-hoc tests were conducted for pairwise comparisons between the different module groups.

\section{3 | RESULTS}

A total of $279 \mathrm{CHC}$ cadres were involved in training conducted at five CHCs: Jagir CHC ( $n=79)$, Gunung Anyar $\mathrm{CHC}(n=61)$, Kalirungkut $\mathrm{CHC}(n=34)$, Sidosermo $\mathrm{CHC}(n=52)$, Tenggilis $\mathrm{CHC}$ ( $n=53$ ) (Table 2); thus giving attendance response rates from $65 \%$ to $93 \%$. All participants were females; while significant differences were reported in terms of participants' age range and occupation across the five $\mathrm{CHCs}$, the majority was housewives in the age group of $>30-50$ years. Most participants reported to have practiced selfmedication less than 10 times in the last month, and sought information regarding their self-medication from doctors and/or community pharmacists (see Table 2).

With regards to the baseline knowledge, Jagir $\mathrm{CHC}$ (indigestion module) group had the highest total pre-test score mean (37.58); while Sidosermo $\mathrm{CHC}$ (general module) group revealed the lowest score mean (31.44) (Table 3). In general, there was an increase in the total post-test scores (knowledge after the training) for the five groups of modules. While the difference between total pre- and post-test scores for the general module group was not significant $(p=.112)$; significant differences were reported for the specific-drug module groups, including indigestion, diarrhoea, analgesic, cough and cold (all $p<.001$ ). Across five basic competencies, significant differences between pre- and post-test scores were reported for competency 1 "drug name and active ingredient", competency 2 "indication" and competency 3 "administration" for all specific-module groups (all $p<.05$ ).

Furthermore, knowledge gain (score difference) reported for the general module group was the lowest $(1.12 ; 95 \% \mathrm{Cl}[-0.45$, $2.92])$; while the common cold module group had the highest (5.02; $95 \% \mathrm{Cl}[1.95,5.17])$ (Table 3). The effect of the type of modules on knowledge gain (score difference) was analysed using multifactorial ANOVA to account the effects of demographics data (i.e., age, education, occupation and income; gender was not included as all participants were females) and self-medication frequencies. The results revealed that there was a significant main effect of the type of modules on score difference values $[F(4,263)=8.37, p<.001]$. The post-hoc tests indicated that score difference values were significantly lower for the general module compared to indigestion, cough and cold, and analgesic modules (all $p \leq .001$ ); however, there was no significant difference with diarrhoea module $(p=.218)$. In addition to the type of modules, age was reported to have a significant main effect on score difference values $(p=.029)$.

\section{4 | DISCUSSION}

This present study has evaluated cadre training using five different types of modules (generic, indigestion, diarrhoea, cough and cold, and analgesic modules) which were developed based on the previous module (Setiadi et al., 2017, 2019). Although the pre-/post-test results in this present study could not be directly compared to those from the previous study since the tests had been modified (Setiadi et al., 2019), this study demonstrated the new modules' capacity to improve knowledge towards OTC medications. This was achieved among CHC cadres in Surabaya Indonesia, particularly with the introduction of specific-drug modules (total pre-test score means versus total post-test score means; all $p<.001)$. It was acknowledged that adult learners tend to connect what they are learning to their previous experiences and they prefer to perceive what they are learning has application to something practical (Alhassan, 2012; Merriam \& Caffaerella, 1999); thus, training materials should be designed to bring the experiential world of adults into the learning process. The use of specific-drug modules in this present study might provide those benefits as they made it easier for participants to connect the learning process with their experiences when using drugs suitable for specific illnesses.

Amongst the specific-drug module groups, the highest knowledge gain was reported for $\mathrm{CHC}$ cadres trained using the cough and cold module (difference score mean 5.02; 95\% Cl [1.95, 5.17]). Based on Surabaya Health Office statistics in 2014, upper respiratory disorders, such as cough and cold, were ranked first among the top 10 health problems across CHCs in Surabaya (Surabaya City Health Office, 2018). While CHC cadres in this present study might be familiar with cough and cold as the commonest health problem in Surabaya, they would easily connect it to their past experiences and/ or possible future situations, thus facilitating a more effective learning process. Furthermore, the specific modules have demonstrated significant benefits in improving knowledge, particulary related to drug name and active ingredients, indication and administration. Further improvements, however, would be required for the module to facilitate improved understanding towards drug classification and additional information (i.e., adverse effects, expiry date, storage/ disposal).

Across $\mathrm{CHCs}$ (five different types of modules), $\mathrm{CHC}$ cadres' characteristics were similar with regards to gender (all were females) and education (approximately 50\% were high-school graduates). This is in line with East Java Provincial Health Office data that $\mathrm{CHC}$ cadres mainly are mothers who are actively involved in Posyandu- a monthly clinic for women and children (a routine health programme of CHCs) (East Java Provincial Health Office, 2018). Furthermore, based on East Java Provincial Statistics in 2015, the average study 


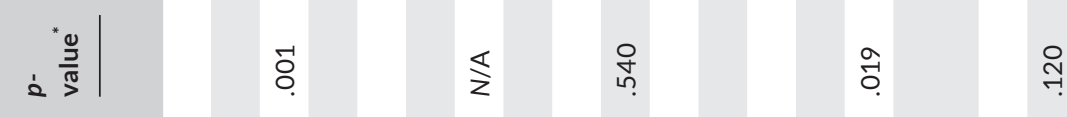

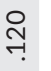

ڤ̊.

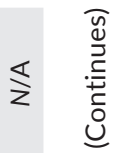

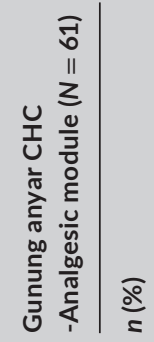

o $\bar{\tau}$

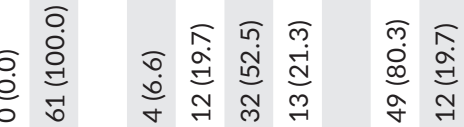

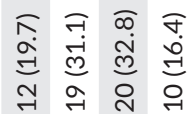

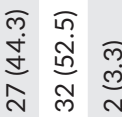

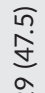

省

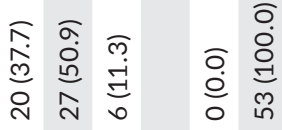

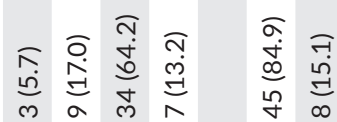

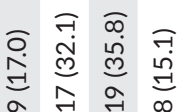

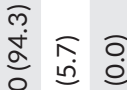

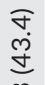

焉

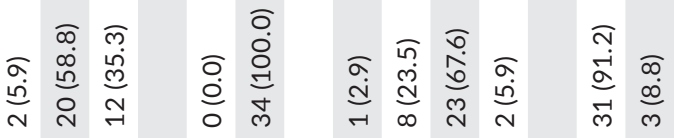

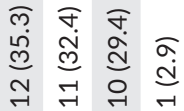

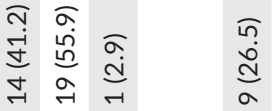

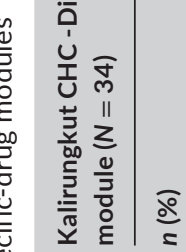

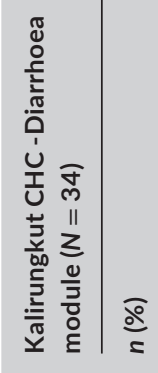

$\frac{1}{\frac{\pi}{\pi}}$

Ф

垔

ह

$\frac{\sqrt{\frac{0}{5}}}{\frac{5}{5}}$

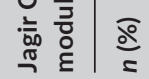

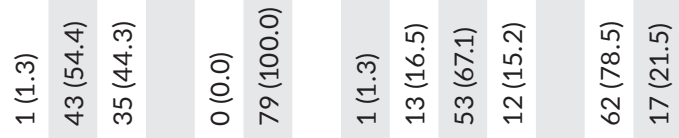

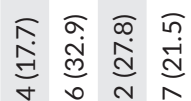

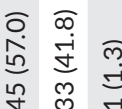



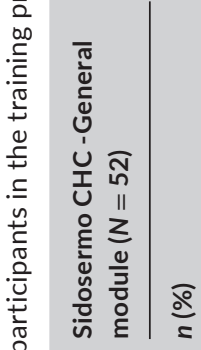

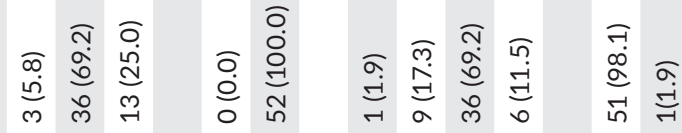

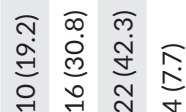

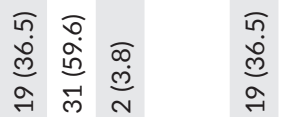

要

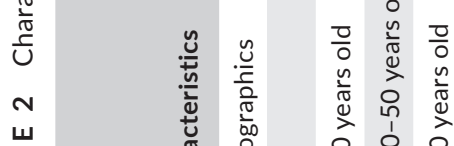

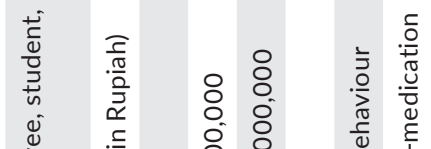

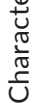

焉 
duration of the Surabayan population was 10.44 years which was equivalent to high-school level (Statistics East Java, 2017). Despite the similarities, significant characteristic differences were found in terms of age and occupation of cadres across $\mathrm{CHCs}$ (five different types of modules). To account for the characteristic variability, a multifactorial ANOVA was used when exploring any associations between type of module and knowledge gained.

Results from the multifactorial ANOVA confirmed that the type of module significantly contributed to the knowledge gained with specific modules generally provided higher knowledge gain than a general module. With regards to participant characteristics, age was found as a significant contributor to the knowledge gain; younger and older participants were reported to obtain higher gains than those in the age range of $30-50$ years (5.3 versus 4.6 versus 3.3 , respectively; $p=.004)$. Women in this age range might bear a larger burden of motherhood responsibilities compared to younger and older women (Monghadam, Khiaban, Esmaeili, \& Salsali, 2017), which might result in less motivation and non-optimal learning process. Studies worldwide have confirmed the effects of socio-demographic factors, such as age, to knowledge and the practice of medicine use, although the findings has been inconsistent (Dawood, Hassali, \& Saleem, 2017; Gualano et al., 2015; Lim \& Teh, 2012).

In addition to the importance of a well-designed module with respect to knowledge gain, this present study highlighted that Surabayan communities have seen doctors as their primary source of self-medication advice. A prior study in East Java reported that the majority of $\mathrm{CHC}$ cadres sought health professionals for self-medication advice, yet the type of health professionals was not differentiated (Setiadi et al., 2019). This might reflect the need for Indonesian pharmacists to establish their roles in promoting responsible self-medication. Community pharmacists are uniquely placed to provide accessible support and advice to the general public compared with other health professionals; moreover, a high level of public trust and confidence in pharmacists' ability to advise on self-medication has been reported (Lynas, 2012; Rutter, 2015; Saxena, 2018). Thus, in addition to pharmacists' established advisory role in pharmacies (Brata et al., 2014; Piecuch \& Kozlowska-Wojciechowska, 2013; Rutter, 2015; Schneider et al., 2011; Suleiman, 2013), the 'GeMa CerMat' initiative could be seen as an opportunity for Indonesian pharmacists to strengthen their role in promoting responsible self medication.

There are some limitations to this study. This study did not provide sample size calculation; however, significance findings between types of modules and score differences $(p<.001$ which was less than alpha of 0.05 ) and the post-hoc power calculation of $>0.9$ might indicate that the power was adequate to detect a difference that was statistically significant. Also, this study included conveniently selected $\mathrm{CHCs}$ and cadres who might have different characteristics compared to the actual community members visiting $\mathrm{CHCs}$ across Surabaya, thus some caution should be exercised in generalising the findings. Furthermore, the allocation of cadres to the five types of modules (interventions) was non-random rather this was based on the setting $(\mathrm{CHC})$, e.g., cadres at Sidosermo 


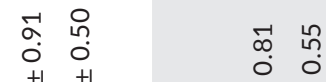

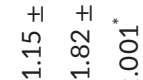

$\begin{array}{ll}0 \\ +1 & +1 \\ 0 & 0\end{array}$

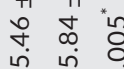

$\stackrel{\infty}{\rightarrow}$ 욱

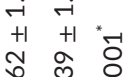

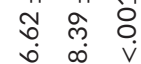

ㅇำ

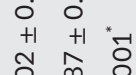

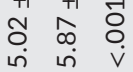

ㄱ. 웍

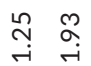

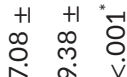

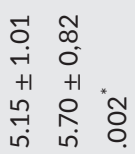

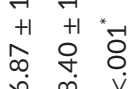

ㅇำ 웅

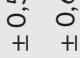

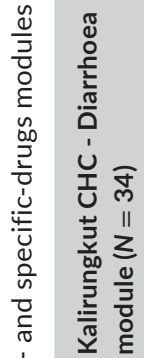

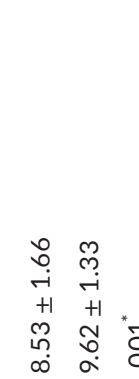

$$
\text { 政 }
$$

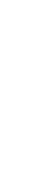$$
\frac{1}{2}
$$

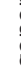$$
\text { . }
$$
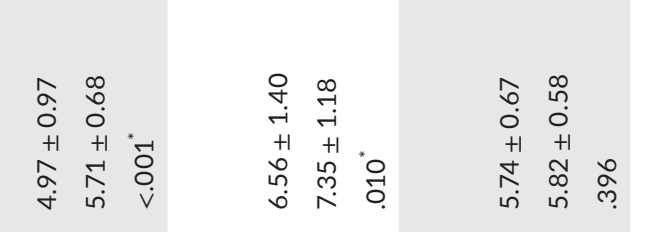

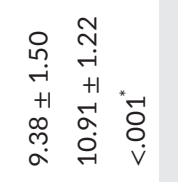

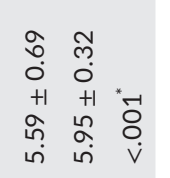

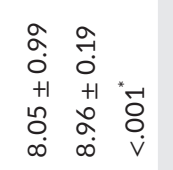
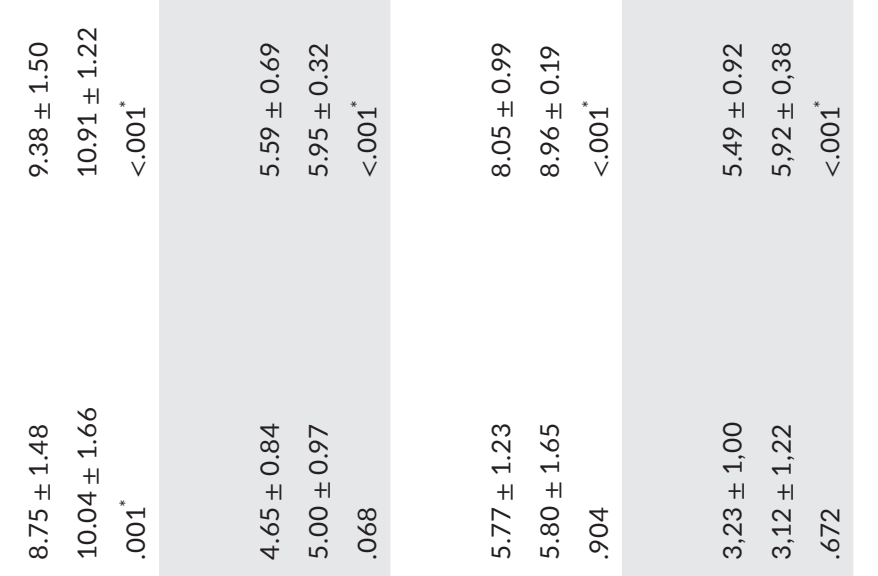

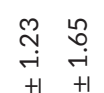

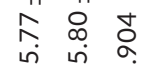

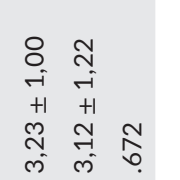

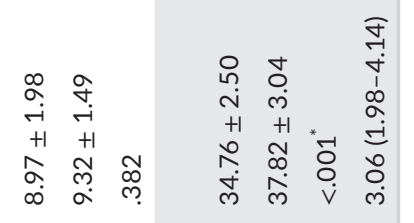
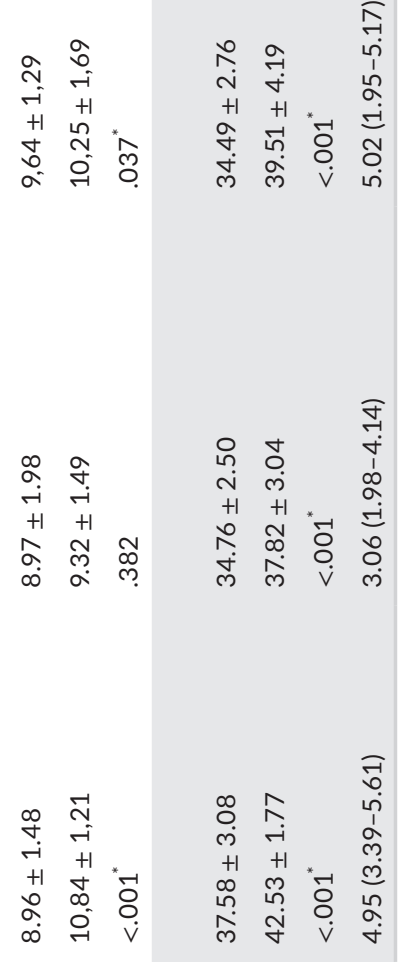

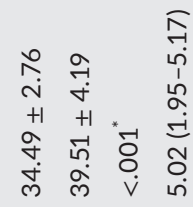
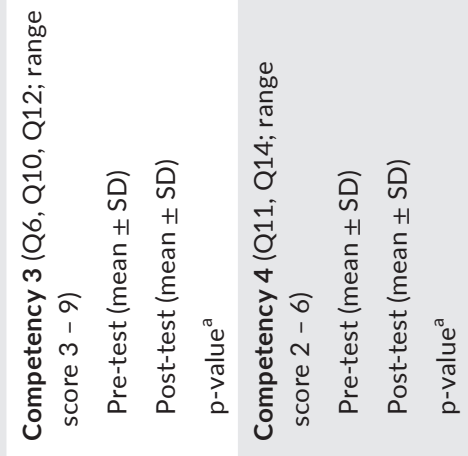

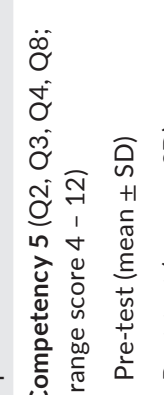
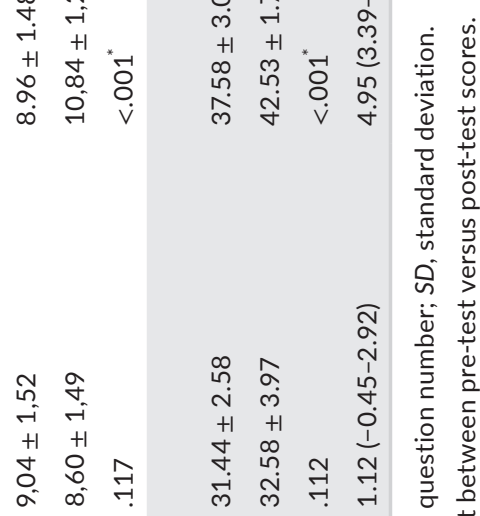

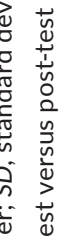

है 으 금 $0 \tilde{y}$ 范

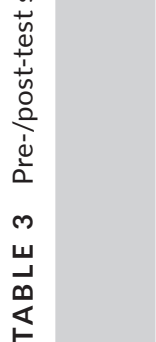


$\mathrm{CHC}$ for general module. However, analysis using multifactorial ANOVA - taking into account the variability of cadres' characteristics across intervention groups (i.e., age, education, occupation and income, and self-medication frequencies) has confirmed the significant effect of type of module to knowledge gain. In addition, the consistent positive results (significant pre-test/post-test differences) among specific-drug module groups might indicate the potential development of modules focusing on specific therapeutic classes for effective community training towards responsible self-medication.

In conclusion, this preliminary work involving $\mathrm{CHC}$ cadres has indicated that the development of modules focusing on drugs for specific minor illnesses could be beneficial in facilitating effective community-based training to promote responsible self-medication in Indonesia. The priority for therapeutic areas chosen for the modules should be based on the local needs and characteristics of the local communities. Further larger scale research would be required to confirm the benefits of specific modules to improve cadres skill to promote responsible self-medication, as well as the impacts to a broader population, including community members.

\section{ACKNOWLEDGEMENTS}

We thank all the participants who took part in this study as well as the chief and staff from the participating Community Health Centres (CHCs) in Surabaya, Indonesia, and the Centre of Medicines Information and Pharmaceutical Care (CMIPC) - Faculty of Pharmacy Universitas Surabaya, for their technical support in making this study possible.

\section{CONFLICTS OF INTEREST}

The authors report no conflicts of interest. The authors alone are responsible for the content and writing of this paper.

\section{ORCID}

Yosi Wibowo iD https://orcid.org/0000-0002-8871-2656

Adji P. Setiadi iD https://orcid.org/0000-0003-1300-373X

Bruce Sunderland (iD https://orcid.org/0000-0001-6214-995X

\section{REFERENCES}

Alhassan, A. (2012). Factors affecting adult learning and their persistence: A theoritical approach. European Journal of Business and Social Sciences, 1, 150-168.

Brata, C., Gudka, S., Schneider, C., \& Clifford, R. (2014). A review of the provision of appropriate advice by pharmacy staff for self-medication in developing countries. Research in Social and Administrative Pharmacy, 11, 136-153.

Dawood, O., Hassali, M., \& Saleem, F. (2017). Factors affecting knowledge and practice of medicine use among the general public in the State of Penang, Malaysia. Journal of Pharmaceutical Health Services Research, 8, 51-57. https://doi.org/10.1111/jphs.12167

Directorate General of Pharmaceutical and Medical Devices, Ministry of Health Republic of Indonesia (MoH-RI) (2015). Ministry of health to initiate 'Smart Use of Medications Movement'(Gerakan Masyarakat Cerdas MenggunakanObat) [Internet]. Retrieved from http://binfar. kemkes.go.id/tag/gema-cermat/\#.WNyy6m997IU
East Java Provincial Health Office (2018). List of cadres [unpublished data]. Surabaya: East Java Provincial Health Office.

Gualano, M., Bert, F., Passi, S., Stillo, M., Galis, V., Manzoli, L., \& Siliquini, R. (2015). Use of self-medication among adolescents: A systematic review and meta-analysis. European Journal of Public Health, 25, 444450. https://doi.org/10.1093/eurpub/cku207

Hartayu, T., Izham, M., \& Suryawati, S. (2012). Improving of type 2 diabetic patients' knowledge, attitude and practice towards diabetes self-care by implementing Community-Based Interactive ApproachDiabetes Mellitus strategy. BMC Research Notes, S:315.

Holt, G., \& Hall, E. (1990). The self-care movement. In E. Feldmann (Ed.), Handbook of Nonprescription drugs. Washington DC: American Pharmaceutcial Association.

Lim, K., \& Teh, C. (2012). A cross-sectional study of public knowledge and attitude towards antibiotics in Putrajaya, Malaysia. Southern Medical Review, 5, 26-33.

Lynas, K. (2012). Professionals you can trust: Pharmacists top the list again in Ipsos Reid survey. Canadian Pharmacists Journal, 145, 55.

Merriam, S., \& Caffarella, R. (Eds.) (1999). Learning in adulthood: A comprehensive guide, (2nd ed.). San Francisco: Jossey Bass.

Ministry of Health Republic of Indonesia (MoH-RI) (2014). Ministry of Health Republic of Indonesia Regulation number 75 year 2014: Community Health Centre (Puskesmas). Jakarta: MOH-RI.

Ministry of Health Republic of Indonesia (MoH-RI) (2016). General guidance on healthy Indonesia program. Jakarta: $\mathrm{MoH}-\mathrm{RI}$.

Ministy of Health Republic of Indonesia (MoH-RI). (2015). Ministry of Health Decree number HK.02.02/MENKES/427/2015: Smart Use of Medication Campaign (Gerakan Masyarakat Cerdas Menggunakan Obat, GeMa CerMat). Jakarta: MoH-RI.

Monghadam, Z., Khiaban, M., Esmaeili, M., \& Salsali, M. (2017). Motherhood challenges and well-being along with the studentship role among Iranian women: A qualitative study. International Journal of Qualitative Studies on Health and Well-being, 12, 1335168. https:// doi.org/10.1080/17482631.2017.1335168

Surabaya City Health Office. (2016). Surabaya health profile year 2016. Surabaya: Surabaya City Health Office.

Piecuch, A., \& Kozlowska-Wojciechowska, M. (2013). Self-medication in Poland: The pharmacists' advisory role in Warsaw. International Journal of Clinical Pharmacy, 35, 225-229. https://doi.org/10.1007/ s11096-012-9734-z

Republic of Indonesia (Rol). (2012). Road map towards National Health Insurance (JKN) 2012-2019. Jakarta: Rol.

Rutter, P. (2015). Role of community pharmacistsin patients' self-care and self-medication. Integrated Pharmacy Research and Practice, 4, 57-65.

Saxena, H. (2018). How Australians rank pharmacists for ethics [Internet]. Retrieved from https://www.pharmacynews.com.au/news/howaustralians-rank-pharmacists-ethics

Schneider, C. R., Everett, A. W., Geelhoed, E., Kendall, P. A., Murray, K., Garnett, P., ... Clifford, R. M. (2011). Provision of primary care to patients with chronic cough in the community pharmacy setting. Annals of Pharmacotherapy, 45, 402-408. https://doi.org/10.1345/ aph.1P514

Setiadi, A., Wibowo, Y., Setiawan, E., Presley, B., Herawati, F., Mulyono, I., \& Wardhani, S. (2017). Introduction to drugs used for self-medication, (1st ed.). Surabaya: CMIPC Universitas Surabaya and East Java Provincial Health Office.

Setiadi, A., Wibowo, Y., Setiawan, E., Presley, B., Mulyono, I., Wardani, S., \& Sunderland, B. (2019). Evaluation of a community-based training to promote responsible self-medication in East Java, Indonesia. International Journal of Pharmacy Practice, 27, 63-70. https://doi. org/10.1111/ijpp.12461

Statistics East Java (BPS Jawa Timur) (2017). The average number of years spent in school for East Java population based on the municipality/ city [Internet]. Retrieved from https://jatim.bps.go.id/dynamictab 
le/2017/09/22/103/rata-rata-lama-sekolah-penduduk-jawa-timur -menurut-kabupaten-kota-ipm-metode-baru-2010-2016.html

Statistics Indonesia (Badan Pusat Statistik-BPS) (2014). Share of Indonesian population who practice self-medication in the last one month based on the provinces and type of medications used, 2000-2014 [Internet]. Retrieved from https://www.bps.go.id/linkTableDinamis/view/id/926

Statistics Indonesia (Badan Pusat Statistik-BPS) (2018). Statistical year book of Indonesia 2018. Jakarta, Indonesia: BPS.

Suleiman, A. (2013). Self-medication and the advisory role of pharmacists in Riyadh, Saudi Arabia. Archives of Pharmacy Practice, 4, 180 185. https://doi.org/10.4103/2045-080X.123228

Surabaya City Health Office (2018). The top 10 diseases in Surabaya JanuaryMay 2017 [Internet]. Retrieved from http://dinkes.surabaya.go.id/porta 1/profil/dkk-dalam-angka/statistik-10-penyakit-terbanyak/

Susantini A. (2006). Implementing CBIA strategy to improve tuberculosis patients' adherence to treatment program (Master thesis). Yogyakarta, Indonesia: Universitas Gajah Mada.
World Health Organisation (WHO) (1998). The role of pharmacists in selfcare and self-medication. Geneva: WHO.

World Health Organisation (2011). World Health Organisation - NCD country profiles: Indonesia. Retrieved from www.who.int/nmh/ countries/idn_en.pdf

How to cite this article: Wibowo Y, Setiadi AP, Halim SV, et al. A pilot study of cadre training to promote responsible self-medication in Indonesia: Which is better specific or general modules?. Health Soc Care Community. 2020;00:1-10. https://doi.org/10.1111/hsc.13118 

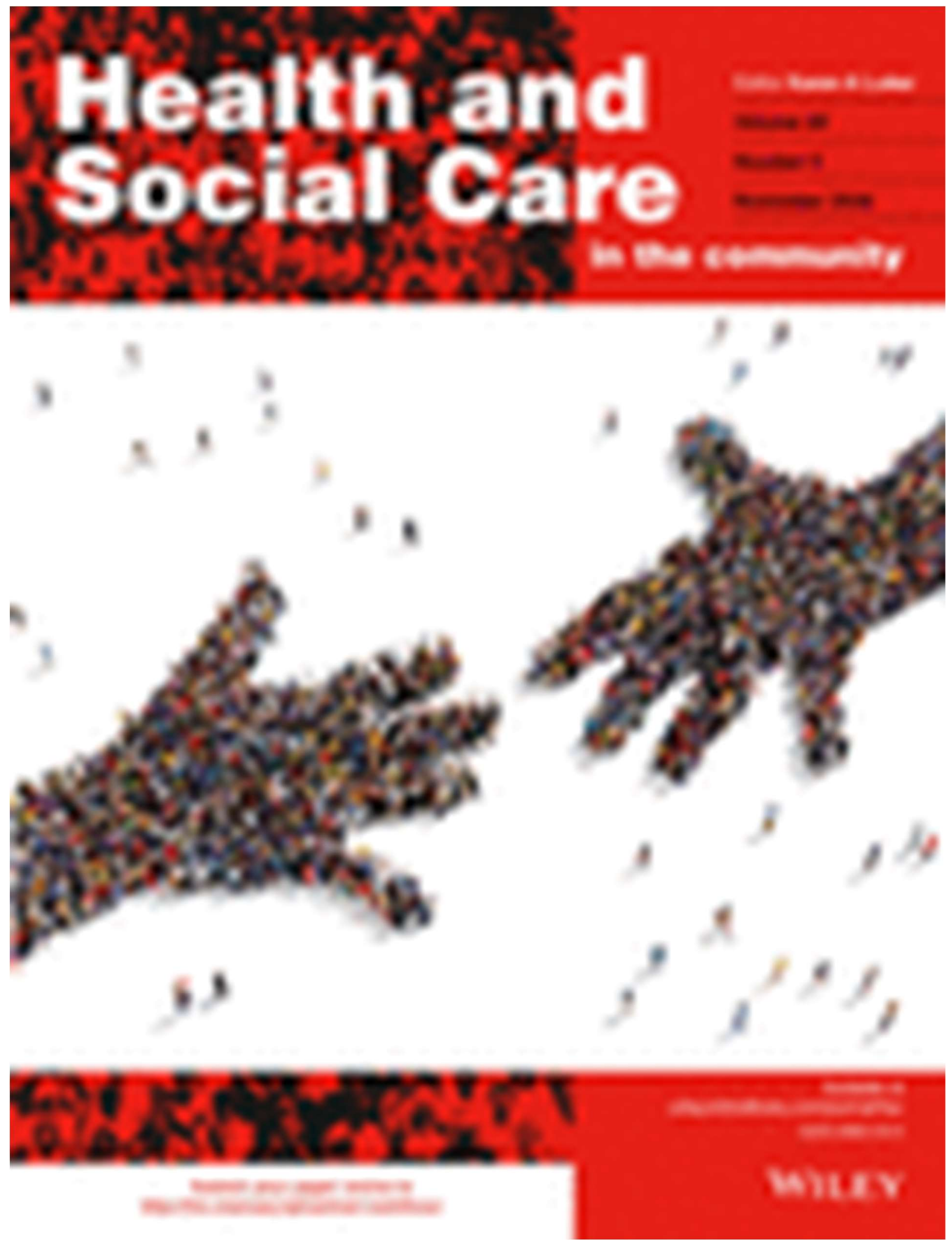


\section{Health and} Social Care in the community

\section{Editor}

Prof. Karen Luker

Health and Social Care in the Community

3rd Floor, Jean McFarlane Building

University of Manchester

Oxford Road

Manchester, M13 9PL

UK Tel: +44 (0) 1613060262

Fax: +44 (0) 1613067867

\section{Statistical Editor}

Dr. Victoria Allgar, The University of York, UK

\section{Reviews Editor}

Prof. Gretl McHugh, University of Leeds, UK

Regional Editor for Australasia

A/Prof. John Parsons, University of Auckland, New Zealand

\section{Regional Editor for North America}

Prof. Karen Chalmers, University of Manchester, Canada
2. Submit an Article

A Browse free sample issue

- Get content alerts

- Subscribe to this journal

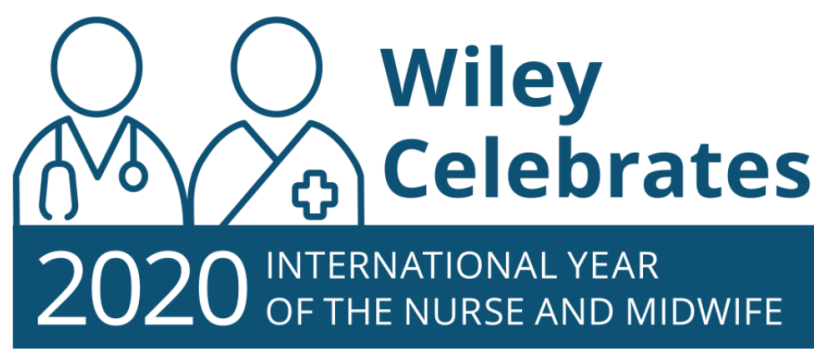

More from this journal

News 


\section{Associate Managing Editor}

Sarah Bremner

email: HSCCoffice@wiley.com

\section{Associate Editors}

Prof. Christine Brown Wilson, Queens University Belfast, Northern Ireland

Dr. Edmond Choi, The University of Hong Kong, Hong Kong

Dr. Alex Hall, University of Manchester, UK

\section{Editorial Board}

Dr. Claudio Bilotta, University of Milan, Italy

Prof. Stephen Birch, McMaster University, Canada

Prof. Marion Bogo, University of Toronto, Canada

Prof. Nicky Britten, Peninsula Medical School, Universities of Exeter and Plymouth, Exeter, UK Dr. Sophia Chan, , University of Hong Kong, Hong Kong, China

Prof. Julianne Cheek, Østfold University College, Norway

Dr. Carman de la Cuesta, Universidad de Alicante, Spain

Dr. Michael Donnelly, Queen's University of Belfast, UK

Dr. Pam Doty, US Department of Health and Human Services, Washington DC, USA

Prof. Jane Hall, University of Technology Sydney, Australia

Prof. Bob Hudson, University of Durham, Durham, UK

Prof. Cathy Humphreys, University of Melbourne, Australia

Prof. Martin Knapp, London School of Economics and Political Science, London, UK

Dr. Christopher Kubiak, Open University, Milton Keynes, UK

Dr. Rosaleen Ow, National University of Singapore, Singapore

A/Prof. Gillian Parker, University of York, York, UK

Prof. David Richards, University of Exeter, Exeter, UK

Dr. Jenny Secker, Anglia Ruskin University, Essex, UK

Prof. Debbie Sharp, University of Bristol, UK
Wiley Job Network

All Virtual Issues

Journal Information

Jobs

Video Abstracts

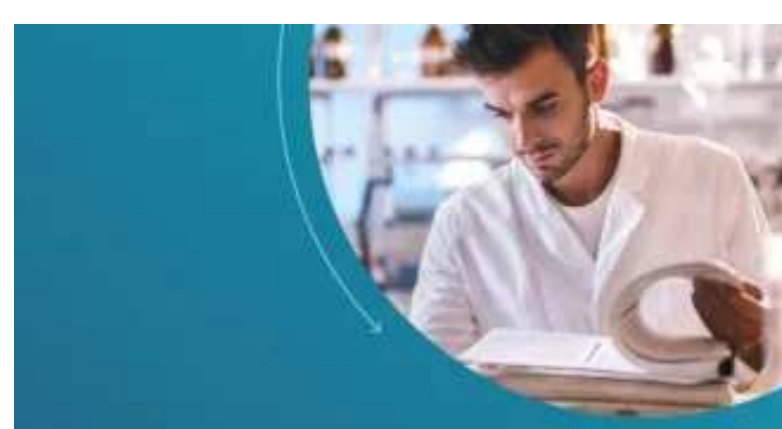

\section{Writing}

\section{for Publication}

An easy-to-follow guide for nurses 


\section{I VERS I TY}

in Research Jobs

Please contact us to see your job listed here

More jobs

About Wiley Online

Library

\section{Privacy Policy}

Terms of Use

\section{Cookies}

Accessibility
Help \& Support

\section{Contact Us}

\section{Subscription Agents}

Advertisers \& Corporate

Partners
Connect with Wiley

The Wiley Network

Wiley Press Room 
Targeting preventive home visits to older adults in disadvantaged communities:

Perspectives of professionals

Maria Kristiansen PhD, Andrea Nedergaard Jensen MSc, Marie Norredam PhD,

Abirami Srivarathan MSc

Version of Record online: 13 August 2020

https://doi.org/10.1111/hsc.13139

Abstract | Full text | PDF | References | Request permissions

Tasmanian healthcare professionals' \& students' capacity for LGBTI + inclusive care: A qualitative inquiry

Ruby Grant BA(hons), PhD, Anthony K. J. Smith BA(hons), GradCertHumanRights,

Lyndsay Newett BA(hons), Meredith Nash MA, PhD,

Richard Turner MBBS (hons), BMedSc, FRACS, PhD, Louise Owen MBBS (hons), FRACGP, FAChSHM

Version of Record online: 12 August 2020

https://doi.org/10.1111/hsc.13130

Abstract | Full text | PDF | References | Request permissions

Association of living density with anxiety and stress: A cross-sectional population study in Hong Kong

Siu Ming Chan MSW, Hung Wong PhD, Roger Yat-Nork Chung PhD, Tat Chor Au-Yeung PhD

Version of Record online: 12 August 2020

https://doi.org/10.1111/hsc.13136

Abstract | Full text | PDF | References | Request permissions

\section{Original Articles}

A pilot study of cadre training to promote responsible self-medication in Indonesia: Which is better specific or general modules?

Yosi Wibowo Ph.D, Adji P. Setiadi Dr., Steven V. Halim M.Pharm., Rama D. Saputra B.Pharm., Rizka Oktavia B. Pharm., Rizky Irianti B. Pharm., Putri I. Lestari B. Pharm, Cecilia R. Puspitasari B.Pharm., Bruce Sunderland Ph.D.

Version of Record online: 12 August 2020

https://doi.org/10.1111/hsc.13118 
Abstract | Full text | PDF | References | Request permissions

\section{ORIGINAL ARTICLES}

The impact of community care services on the preference for ageing in place in urban China

Junshan Zhou Ph.D, Alan Walker CBE, FBA, FAcSS, FGSA

Version of Record online: 12 August 2020

https://doi.org/10.1111/hsc.13138

Abstract | Full text | PDF | References | Request permissions

อ. Open Access

To live with a wagging tailed assistant - Service and hearing dog ownership from the perspective of Swedish owners

Martina Lundqvist MSc, Lars-Åke Levin PhD, Jenny Alwin PhD, Ann-Charlotte Nedlund PhD

Version of Record online: 11 August 2020

https://doi.org/10.1111/hsc.13128

Abstract | Full text | PDF | References | Request permissions

Effect of socio-demographic characteristics on social security in northeast China Wei Xian, Cheng Jin, Bing Han, Xueying Xu, Lu Zhang, Hongbo Liu

Version of Record online: 11 August 2020

https://doi.org/10.1111/hsc.13127

Abstract | Full text | PDF | References | Request permissions

Mindfulness and social-emotional skills in Latino pre-adolescents in the U.S.: The mediating role of executive function

Shuang Lu, Chien-Chung Huang, Shannon P. Cheung, Juan A. Rios, Yafan Chen

Version of Record online: 11 August 2020

https://doi.org/10.1111/hsc.13135

Abstract | Full text | PDF | References | Request permissions 


\title{
SJR
}

\section{Health and Social Care in the Community}

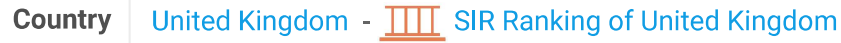 \\ Subject Area and Medicine \\ Category Health Policy \\ Public Health, Environmental and Occupational Health \\ Social Sciences \\ Social Sciences (miscellaneous) \\ Social Work \\ Sociology and Political Science \\ Publisher Wiley-Blackwell Publishing Ltd \\ Publication type Journals \\ ISSN 09660410,13652524 \\ Coverage 1993-2020 \\ Scope Health and Social Care in the Community is an international peer-reviewed journal with a multidisciplinary audience \\ including social workers, health care professionals with a community or public health focus e.g. public health practitioners, \\ GP's, Community Nurses and Social Care researchers and educators. The Journal promotes critical thinking and informed \\ debate about all aspects of health and social care. Original papers are sought that reflect the broad range of policy, practice \\ and theoretical issues underpinning the provision of care in the community. Health and Social Care in the Community \\ publishes systematic and narrative reviews, policy analysis and empirical qualitative or quantitative papers including \\ papers that focus on professional or patient education. \\ Homepage \\ How to publish in this journal \\ Contact \\ Join the conversation about this journal
}




\section{Ads by Google}

Stop seeing this ad Why this ad? (i)

Quartiles
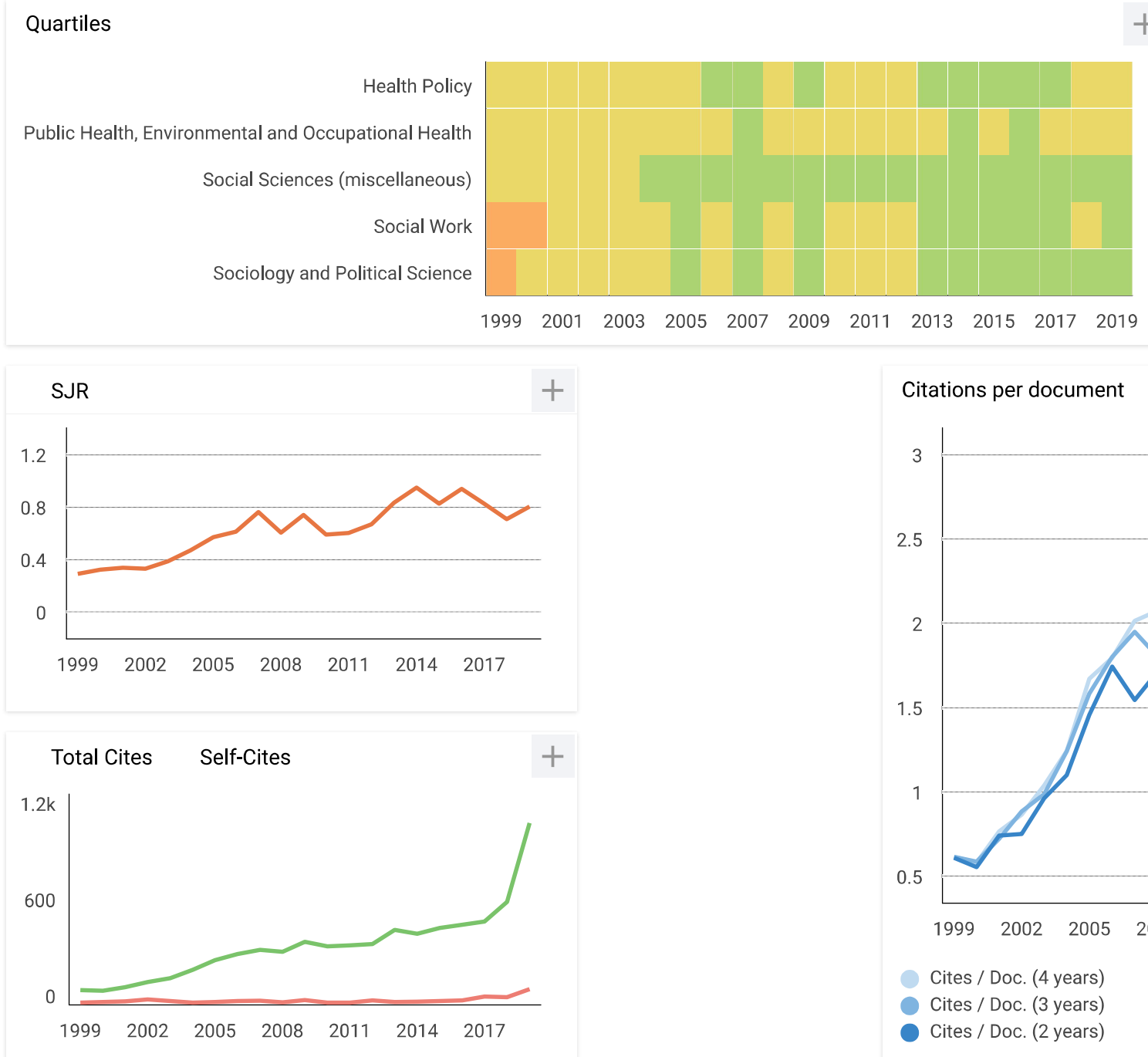

Citations per document

$\begin{array}{llllll}2002 & 2005 & 2008 & 2011 & 2014 & 2017\end{array}$
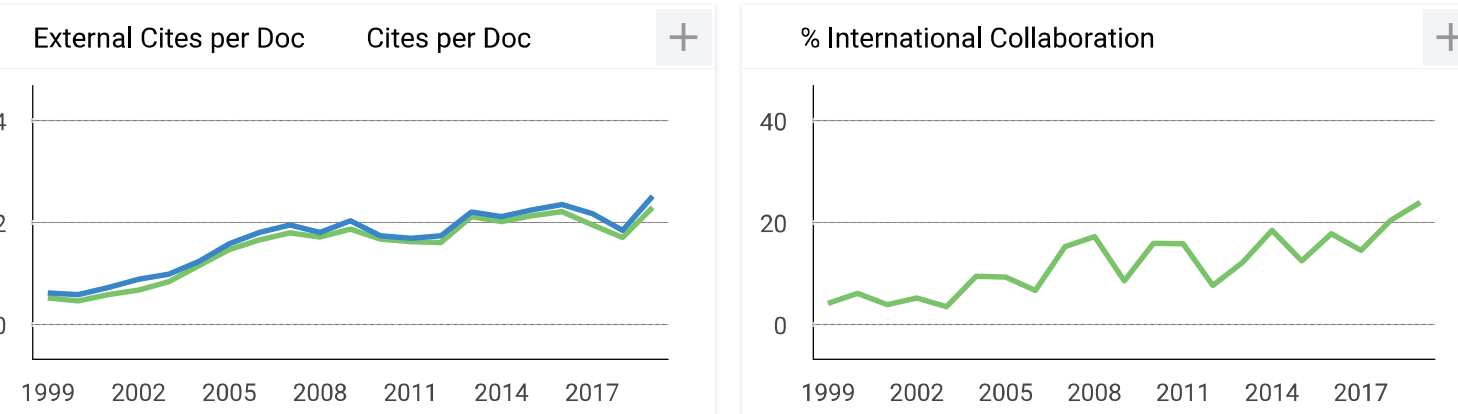

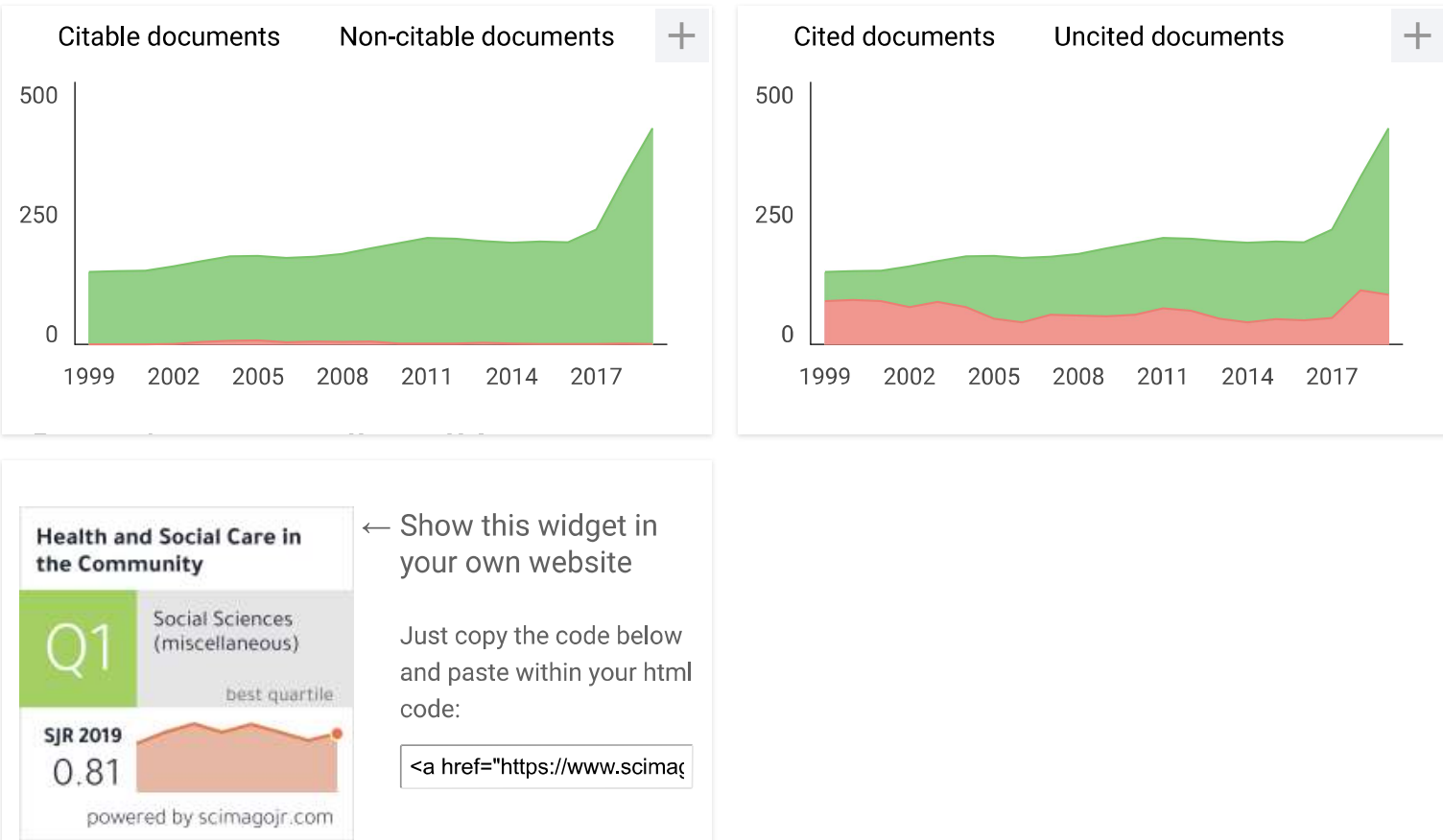

\section{IJENS Journals}

IJENS publisher SCOPUS - indexed; Call For Papers

\section{Leave a comment}

Name

Email

(will not be published) 
The users of Scimago Journal \& Country Rank have the possibility to dialogue through comments linked to a specific journal. The purpose is to have a forum in which general doubts about the processes of publication in the journal, experiences and other issues derived from the publication of papers are resolved. For topics on particular articles, maintain the dialogue through the usual channels with your editor.

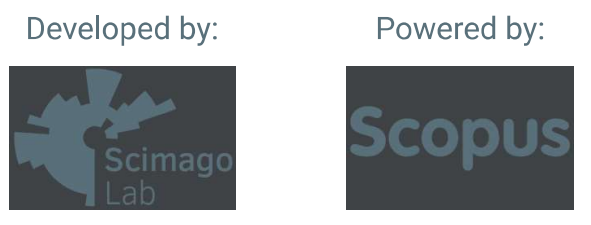

Follow us on @ScimagoJR

Scimago Lab, Copyright 2007-2020. Data Source: Scopus ${ }^{\circledR}$
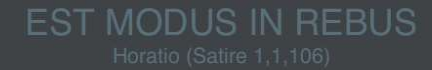